\title{
The management of brain metastases in non-small cell lung cancer
}

\author{
Scott Owen ${ }^{1 *}$ and Luis Souhami ${ }^{2}$ \\ 1 Division of Medical Oncology, Department of Oncology, McGill University Health Centre, Montreal, OC, Canada \\ 2 Division of Radiation Oncology, Department of Oncology, McGill University Health Centre, Montreal, QC, Canada
}

\section{Edited by:}

Barbara Melosky, British Columbia

Cancer Agency, Canada

Reviewed by:

Sacha I. Rothschild, University

Hospital Basel, Switzerland

Weiqiang Zhao, The Ohio State

University Wexner Medical Center,

USA

\section{${ }^{*}$ Correspondence:}

Scott Owen, Montreal General Hospital, 1650 Cedar Avenue, T7-402,

Montreal, OC H3G 1A4, Canada

e-mail:scott.owen@mcgill.ca
Brain metastases (BM) are a common and lethal complication of non-small cell lung cancer (NSCLC), which portend a poor prognosis. In addition, their management implies several challenges including preservation of neurological and neurocognitive function during surgery or radiation-therapy, minimizing iatrogenic complications of supportive medications, and optimizing drug delivery across the blood-brain barrier. Despite these challenges, advancements in combined modality approaches can deliver hope of improved overall survival and quality of life for a subset of NSCLC patients with BM. Moreover, new drugs harnessing our greater understanding of tumor biology promise to build on this hope. In this mini-review, we revised the management of BM in NSCLC including advancements in neurosurgery, radiation therapy, as well as systemic and supportive therapy.

Keywords: brain metastases, lung cancer, targeted therapy, radiation therapy, chemotherapy, stereotactic radiosurgery, surgery

\section{INTRODUCTION}

Lung cancer is the leading cause of cancer mortality worldwide, accounting for 1.38 million annual deaths, representing $18.2 \%$ of total deaths from cancer (1). Among those, approximately $7.4 \%$ of non-small cell lung cancer (NSCLC) patients will have brain metastases (BM) at presentation (2), and 25-30\% will develop BM during the course of their disease (3). Lifeexpectancy for these patients is poor, with a median survival of only 3.4 months (4). Moreover, many will suffer considerable loss of autonomy due to neurocognitive and functional deficits, as well as morbidity associated with medications such as steroids and anti-epileptic drugs.

Despite these grim realities, there is room for optimism among identifiable subsets of these patients. A recent published series of NSCLC patients with synchronous BM receiving surgery or radiosurgery to the brain and aggressive management of their extracranial disease reported a median overall survival (OS) of 12.1 months (5). Improved surgical techniques and radiation therapy (RT) technology, as well as more effective systemic treatments and multimodality approaches have led to these superior outcomes. Moreover, renewed hope has emerged from the use of smallmolecule drugs targeting oncogenic mutations, which have shown promising activity both extra-cranially and intra-cranially (6).

\section{PROGNOSTIC FACTORS}

Several variables have been established of prognostic importance in determining potential outcomes for patients harboring BM. In 1997, the Radiation Therapy Oncology Group (RTOG) performed a recursive partitioning analysis (RPA) from a historical database of 1200 patients treated with whole-brain radiation therapy (WBRT) from three RTOG BM trials and published a prognostic scoring system (7). Three scoring classes were identified based on patients' Karnofsky performance score (KPS), age, status of primary tumor, and extent of extracranial disease (Table 1). Median survival ranged from 2.3 months for patients in class III to 7.1 months for those in class I.

Since then, several other scoring classifications have been described $(4,8-11)$ as shown in Table 1 . All these classifications have limitations, but are able to consistently prognosticate outcomes based on the defined scoring. Irrespective of the scoring classification used, age, performance status, number of brain lesions, and the presence of extracranial metastases are the variables that better define prognosis. Given the high heterogeneity of the BM patient population, one should not rely exclusively on these indices when assessing the management for such patients. A comparative review of five of these prognostic indexes using an artificial neural network in patients with BM and receiving WBRT (12) suggests that the graded prognostic assessment index (10) was the most powerful in predicting survival.

Increasingly, molecular biomarkers are also being identified with prognostic significance in NSCLC, some with positive [e.g., EGFR (del-19 and L858R)] and others with negative (e.g., ERCC1, BRCA1, TP53, and KRAS) prognostic value (13). In addition, microarray-derived gene signatures provide the potential for even greater prognostic ability (14). However, many of these biomarkers require further validation, and are not yet ready for entry into routine clinical practice.

\section{TREATMENT}

\section{SUPPORTIVE}

Early integration of palliative care in the management of metastatic NSLCC has been demonstrated to improve both quality of life and mood, and is associated with improved survival despite less aggressive end of life treatment (15). In addition to general palliative measures, patients with $\mathrm{BM}$ often necessitate additional supportive medications such as steroids and anti-seizure medications. 
Table 1 | Prognostic indexes for metastatic brain disease

\begin{tabular}{ll}
\hline RECURSIVE PARTITIONING ANALYSIS \\
Class 1 & $\begin{array}{l}\text { Age }<65 ; \mathrm{KPS} \geq 70 \text {, primary controlled; no extra-cranial } \\
\text { disease }\end{array}$ \\
Class 2 & $\begin{array}{l}\text { Patients not in class } 1 \text { or } 2 \\
\text { Class } 3\end{array}$ \\
\hline
\end{tabular}

\section{BASIC SCORE FOR BRAIN METASTASES}

Score 0 KPS 50-70; primary uncontrolled; extra-cranial disease present

Score 1 KPS 80-100; primary controlled; no extra-cranial disease

\section{SCORE INDEX FOR RADIOSURGERY}

Score $0 \quad K P S \leq 50$; age $\geq 60$; extra-cranial disease progressive; lesions $\geq 3$; volume $>13 \mathrm{ml}$ (largest lesion)

Score 1 KPS 60-70; age 51-50; extra-cranial disease stable; lesion 2; volume $5-13 \mathrm{ml}$

Score $2 \quad K P S>80$; age $\leq 50$; systemic disease NED; lesion 1; volume $<5$

\section{GRADED PROGNOSTIC ASSESSMENT}

Score $0 \quad K P S<70$; age $>60$; lesions $>3$; extra-cranial disease present

Score 0.5 KPS 70-80; age 50-59; lesions 2-3

Score $1 \quad$ KPS 90-100; age $<50$; lesion 1; no extra-cranial disease

KPS, Karnofsky performance status; NED, no evidence of disease.

Corticosteroids can be vital drugs in the control of intracranial edema from BM and the relief of related symptoms. However, in light of their considerable short- and long-term side effects, steroids should be used judiciously. Hence, a systematic review on the subject (16) has made the following recommendations:

- If corticosteroids are given, dexamethasone is the best choice (level 3).

- Starting doses of 4-8 mg of dexamethasone should be given for temporary relief of symptoms related to increased intracranial pressure. In more severe cases, where symptoms suggest impending herniation, doses of $16 \mathrm{mg}$ /day or more may be considered (level 3).

- There is insufficient evidence to guide treatment recommendations for asymptomatic BM.

\section{SURGERY}

Up to few decades ago, surgical resection was mainly used to establish a diagnosis or to alleviate mass-effect symptoms. More recently, its definitive role in improving disease control for patients with single, resectable metastasis has been shown to be significant. Three randomized studies (17-19) have addressed the potential therapeutic value of surgical resection by comparing surgery followed by WBRT vs. WBRT alone in patients with a single brain metastasis (Table 2).

In two of these trials $(17,18)$, a survival benefit was reported for patients undergoing the combined approach. Patchell et al. (17) randomized 48 good-performing (KPS $\geq 70$ ) patients with an MRI-diagnosed, tissue-proven single lesion to surgical resection plus WBRT (36 Gy in 12 fractions) vs. WBRT alone. Of interest, $11 \%$ of patients were excluded because no metastatic disease was seen on the biopsy specimens. The authors reported a statistically significant improvement in survival (median survival: 40 vs. 15 weeks, $p<0.01$ ) favoring the combined therapy, as well as a reduction in brain recurrence rates and neurologic death. Vecht at al. (18) compared WBRT ( $40 \mathrm{~Gy}$ in 20 fractions) with the same WBRT preceded by surgery. Similarly, the combined approach showed a survival advantage (median survival: 10 vs. 6 months, $p=0.04$ ). In this study, patients were stratified for progressive vs. stable extracranial disease, which proved to be the most important prognosticator for survival.

In contrast, the study by Mintz et al. (19) failed to show a survival benefit when WBRT ( 30 Gy in 10 fractions) followed surgical resection. The median survival for the WBRT group was 6.3 vs. 5.6 months for the combined modality group $(p=0.24)$. The median survival in the Mintz et al. (19) series was lower than the two other randomized studies and may be explained by the selection of patients with lower KPS or with more extensive extra cranial systemic disease (45\% of patients). In addition, MRI was not routinely used to exclude multiple metastases.

It should be mentioned that all of these randomized studies had small patient numbers and did not include relatively radiosensitive tumors such as small cell lung cancer, lymphoma, myeloma, and germ cell tumors. Also, these trials were not specific for NSCLC patients, although this histology was the predominant one in all trials.

Despite these limitations, the current level 1 evidence supports the use of WBRT post-surgical resection in patients with a single, resectable lesion, good performance, and limited extracranial disease. For patients with multiple metastatic lesions, poor performance scores, and extensive systemic disease an evidence-based recommendation for the combined approach cannot be made.

A follow-up trial by Patchell and colleagues (24) addressed the real need of WBRT post-resection of a single brain metastasis. In a multi-center study, 95 patients (60\% with NSCLC) with KPS $\geq 70$ undergoing a complete resection of a single brain metastasis were randomized to WBRT ( $50.4 \mathrm{~Gy}$ in 28 fractions) or no further treatment for a primary end-point of tumor recurrence anywhere in the brain. A total of 95 patients were randomized and again NSCLC was the predominant tumor type. The group receiving post-operative WBRT experienced a significantly lower rate of brain recurrence (18 vs. $70 \%, p<0.001$ ). WBRT also decreased brain recurrence at the site of the original metastasis ( 10 vs. $41 \%$, $p<0.001)$ and at other sites in the brain $(14$ vs. $37 \%, p<0.01)$. Although OS was not different between groups, importantly, postoperative WBRT significantly prevented death from neurologic causes ( 14 vs. $44 \%, p=0.003$ ). This trial defined the need for adjuvant RT post-resection of a single brain metastasis.

\section{RADIATION THERAPY WHOLE-BRAIN RADIATION THERAPY}

The use of WBRT for patients harboring BM is considered by many as the standard treatment. The rationale for treating the whole brain is based on the presumption that micro-metastatic deposits of tumor cells are present elsewhere in the brain. WBRT is the 
Table 2 | Randomized trials of WBRT in brain metastases

\begin{tabular}{|c|c|c|c|c|c|}
\hline Author & No. patients & Randomization & Local control & Survival (months) & $p$ Value \\
\hline \multicolumn{6}{|c|}{ WBRT \pm SURGERY } \\
\hline \multirow[t]{2}{*}{ Patchell (7) } & 48 & WBRT & $48 \%$ & 3.6 & $p<0.001$ \\
\hline & & $\mathrm{S}+\mathrm{WBRT}$ & $80 \%$ & 9.5 & \\
\hline \multirow[t]{2}{*}{ Vecht (8) } & 63 & WBRT & NR & 6.0 & $p=0.04$ \\
\hline & & $\mathrm{S}+$ WBRT & & 10.0 & \\
\hline \multirow[t]{2}{*}{ Mintz (9) } & 84 & WBRT & NR & 6.3 & $p=0.39$ \\
\hline & & $\mathrm{S}+\mathrm{WBRT}$ & & 5.6 & \\
\hline Author & No. patients & Randomization & Local control (\%) & Survival (months) & Neurologic death \\
\hline \multicolumn{6}{|c|}{ WBRT \pm STEREOTACTIC RADIOSURGERY } \\
\hline \multirow[t]{2}{*}{ Chougule (23) } & 73 & SRS & 87 & 5 & NR \\
\hline & & $\mathrm{SRS}+\mathrm{WBRT}$ & 91 & 9 & \\
\hline \multirow[t]{2}{*}{ Aoyama (34) } & 132 & SRS & 72.5 & 7.5 & $19.3 \%$ \\
\hline & & $\mathrm{SRS}+\mathrm{WBRT}$ & 88.7 & 8 & $22.8 \%$ \\
\hline \multirow[t]{2}{*}{ Chang (35) } & 58 & SRS & 67 & 15.2 & NR \\
\hline & & $\mathrm{SRS}+\mathrm{WBRT}$ & 100 & 5.7 & \\
\hline \multirow[t]{2}{*}{ Kocher (36) } & 199 & SRS & 69 & 10.7 & $44 \%$ \\
\hline & & SRS + WBRT & 81 & 10.9 & $28 \%$ \\
\hline
\end{tabular}

No, number; S, surgery; SRS, stereotactic radiosurgery; WBRT, whole brain radiation therapy; NR, not reported.

most frequently used treatment for the management of BM and its use is associated with improvement in neurologic symptoms and decreased neurologic death (25). The RTOG and other investigators (26-31) conducted several randomized trials evaluating different dose/fractionation regimens, but no particular regimen appears to be superior in terms of disease control or survival. Typically, a dose of 20 Gy in 5 fractions or 30 Gy in 10 fractions is recommended. Approximately $60 \%$ of patients will experience a complete or partial response with a similar rate for symptoms improvement, though usually transient.

One major concern with the use of WBRT is the risk of neurocognitive deficits, particularly short-term memory. Unfortunately, the real rate and magnitude of neurocognitive deficits post-WBRT has not been properly studied. It has been shown that over $90 \%$ of patients with BM had impairment in one or more neurocognitive tests at baseline and prior to WBRT (32). Proponents of WBRT argue that it is the disease progression in the brain not treated by WBRT that, in fact, compromises the patient's neurocognitive function. However, some patients develop cognitive problems that cannot be simply explained by disease progression elsewhere in the brain. Late effects from WBRT are usually seen after 6 months post-treatment and are secondary to white matter damage. Considering that many patients will not survive beyond 6 months, it is plausible to consider that cognitive deficits would be seen in larger proportion of patients should they survive longer. For a comprehensive review of the subject, we recommend the paper by McDuff et al. (33).
Recent approaches to reduce the potentially negative effects of WBRT on cognitive function include the concomitant use of memantine (20) and hippocampal sparing during WBRT (21). Memantine, a potential neuroprotector, was used during EBRT in a recent RTOG randomized trial (20). Patients receiving the drug had improved cognitive function in several domains. Gondi et al. (21) presented a phase II RTOG study of hippocampal sparing in patients undergoing WBRT for BM. Although this was a single arm trial, the declines in cognitive function are less than what was observed from historical controls.

\section{STEREOTACTIC RADIOSURGERY}

Stereotactic radiosurgery (SRS) delivers a single high dose of irradiation to the target volume while avoiding the surrounding normal tissues. A randomized trial conducted by the RTOG (22) showed that the addition of SRS to WBRT was superior to WBRT alone in patients with a newly diagnosed single brain lesion. A survival benefit was not seen for patients with two or three metastatic lesions, although local brain control was significantly improved with the addition of SRS. Given its focal delivery of irradiation, there have been concerns that its isolated use could lead to an increased rate of failure elsewhere in the brain. However, concerns with cognitive deficits from WBRT led investigators to use SRS alone in selected patients, reserving WBRT for a later date if necessary.

To address to this question, four randomized trials have, to date, compared SRS alone vs. SRS plus WBRT in patients with a 
limited number of metastatic lesions $(23,34-36)$. One of them has only been reported in abstract form (23). Table 2 summarizes the results of these trials.

Despite differences in patient selection and treatment design, all trials consistently show no significant difference in survival, but have shown a significant reduction in intracranial failures and death from brain causes. One study (35) had a neurocognitive endpoint - Hopkins Verbal Learning Test (HVLT) - at 4 months posttreatment. This small study was stopped prematurely because an interim analysis showed neurocognitive function at 4 months significantly worse after SRS + WBRT than after SRS alone, although brain control at 1 year was significantly better for the WBRT + SRS arm ( 73 vs. $27 \%, p=0.0003)$. On the other hand, in the Japanese trial (34), there was a significant decline in mini-mental score when SRS was given alone making the authors conclude that BM control was the most important factor for preserving neurocognitive function.

Whether SRS can replace WBRT in newly diagnosed BM remains to be determined and treatment decisions should be individualized taking into consideration the patients' wishes, age, intra and extracranial disease extent, and prognosis.

\section{CHEMOTHERAPY}

Due to the failure of most drugs to cross the intact blood-brain barrier (BBB), the role of chemotherapy in the treatment of BM has been viewed critically (2). Chemotherapy drugs are generally large ( $>150 \mathrm{kDa})$, ionized, hydrophilic, and often protein-bound, and therefore, ill-suited to penetrate the tight-junctions, electrochemical barrier, astrocyte foot-processes, and highly regulated transmembrane transport proteins of the central nervous system's endothelial vasculature (37).

However, the effects of the BBB may be over-estimated. First, there is evidence that the $\mathrm{BBB}$ of $\mathrm{BM}$ is disrupted, as evidenced by the presence of peritumoral edema and the accumulation of contrast media during computed tomography or magnetic resonance assessments $(38,39)$. Second, there is evidence of intracranial tumor response, even to drugs that in healthy systems have little central nervous system penetration. In a recent review (37), the response rates (RRs) of BM to platinum-based regimens in seven clinical trials of treatment-naïve NSCLC patients were similar to those achieved extra-cranially, ranging from 30 to 50\%. However, the median survival remained only $5-8$ months in most cases. In the same review, three trials using temozolomide achieved a RR of only $0-10 \%$, suggesting that the selection of chemotherapy drugs should be based mainly on their established anti-tumor activity to extracranial sites, and not on considerations of BBB penetrance.

More recently, two phase II trials have examined the use of cisplatin and pemetrexed for the treatment of NSCLC with BM. In one trial, 43 chemo-naive NSCLC patients (93\% non-squamous histology) with $\mathrm{BM}$ received up to six cycles of cisplatin and pemetrexed at standard doses (40). WBRT was given in cases of disease progression or at chemotherapy completion. Cerebral, extracerebral, and objective RRs by intention to treat (ITT) were 41.9, 34.9 , and 34.9\%, respectively. Median OS and progression-free survival (PFS) were 7.4 and 4.0 months, respectively.

In another phase II trial (41), newly diagnosed NSCLC patients with BM received up to six cycles of cisplatin and pemetrexed concurrently with WBRT (30 Gy/10 fractions) during days 1-12 of the first cycle. Among the 41 patients evaluable for response ( $100 \%$ adenocarcinoma), the cerebral, extra-cerebral, and overall RRs were 68.3, 34.1, and 36.6\%, respectively. The median PFS of $\mathrm{BM}$ and OS were 10.6 and 12.6 months, respectively. The hematologic toxicities were generally mild or moderate and there were no grade 4 or higher non-hematologic toxicities. The combined treatment was generally safe and well-tolerated.

\section{TARGETED THERAPY}

The use of drugs targeting the proteins of mutated EGFR and anaplastic lymphoma kinase (ALK) genes has become standard of care in the systemic treatment of metastatic NSCLC (42). In firstline clinical trials of the EGFR-targeted drugs gefitinib, erlotinib, and afatinib, objective response rates (ORRs) of $55-83 \%$ were observed, mostly clustering above $70 \%$ (43). In addition, large international phase III trials comparing EGFR tyrosine kinase inhibitors (TKIs) against platinum doublet chemotherapy have achieved significant PFS benefits of $>4$ months with hazard-ratios (HRs) ranging from 0.37 to 0.58 , and improvements to symptoms and quality of life (44-47).

The ALK-inhibitor crizotinib has also demonstrated strong anti-tumor activity systemically. In a phase III second-line NSCLC trial of patients with ALK-rearranged tumors randomized to receive crizotinib vs. chemotherapy with docetaxel or pemetrexed, an $\mathrm{ORR}=65 \%$ was demonstrated, as well as a PFS benefit of 4.7 months vs. chemotherapy (7.7 vs. 3.0 months, HR $0.49, p<0.001$ ) (48). Similarly, in a phase I study of the newer ALK-inhibitor ceritinib, an ORR $=58 \%$ was achieved, including an ORR $=56 \%$ in tumors that had progressed on crizotinib (49).

The mutation status of tumors is usually derived from biopsies obtained at extracranial sites, and thus, does not necessarily guarantee a mutation in the sub-clones within the brain. However, a Chinese study of 136 NSCLC patients with resected BM, in which an EGFR mutation was identified in $57 \%$ of the BM, found a concordance rate of $93.3 \%$ in the EGFR mutation status between the primary tumor and BM (50). This suggests that primary tumor EGFR status is a very good surrogate for EGFR mutation status of the BM. In this same cohort of patients, the median OS was 24.5 months in the EGFR mutation group, compared to 15 months in the wild-type group. This finding is consistent with other studies identifying EGFR mutation status as a positive prognostic factor among patients with BM (51).

Just as targeted therapy with EGFR and ALK inhibitors is highly active systemically among molecularly selected NSCLC patients, there is mounting evidence that this is also true for activity intracranially. A recent review has examined the use of the EGFR inhibitors gefitinib and erlotinib in BM among NSCLC patients (6). In the eight phase II clinical trials included in the review, the intracranial RRs with gefitinib were $27-32 \%$ in unselected patients, $43 \%$ in an Asian population without molecular selection, and 70 $89 \%$ in molecularly selected patients. Similarly, intracranial RRs were 56 and $82 \%$ for erlotinib in clinically and molecularly selected patients, respectively. Taken together, these results highlight both robust intracranial activity and the importance of EGFR mutation status as a predictor of intracranial response. In addition, for the 
three studies where OS data were presented, the median OS results were $12.9,18.8$, and 19.8 months, respectively.

\section{CONCLUSION}

The management of patients with BM has evolved over the years from an under-studied area to a field of exciting active research. Supportive therapy, surgery, and RT remain the mainstays of management for these patients. Additional areas of active research include techniques to preserve neurocognitive functions with radiotherapy $(20,52)$, improving the detection and clinical utility of circulating tumor cells (53), and novel systemic approaches including immunotherapy alone $(54,55)$ or in combination with radiotherapy (56), anti-metabolic agents (57), anti-angiogenesis drugs (58), and novel targeted therapies for a growing list of oncogenic mutations (59). Ultimately, the optimal management strategy will employ a multi-disciplinary approach accounting for individual characteristics of both patient and tumor.

\section{REFERENCES}

1. Jemal A, Bray F, Center MM, Ferlay J, Ward E, Forman D. Global cancer statistics. CA Cancer J Clin (2011) 61(2):69-90. doi:10.3322/caac.20107

2. Schuette W. Treatment of brain metastases from lung cancer: chemotherapy. Lung Cancer (2004) 45(Suppl 2):S253-7. doi:10.1016/j.lungcan.2004.07.967

3. Langer CJ, Mehta MP. Current management of brain metastases, with a focus on systemic options. J Clin Oncol (2005) 23(25):6207-19. doi:10.1200/jco.2005. 03.145

4. Lagerwaard FJ, Levendag PC, Nowak PJ, Eijkenboom WM, Hanssens PE, Schmitz PI. Identification of prognostic factors in patients with brain metastases: a review of 1292 patients. Int J Radiat Oncol Biol Phys (1999) 43(4):795-803. doi:10.1016/S0360-3016(98)00442-8

5. Lind JS, Lagerwaard FJ, Smit EF, Postmus PE, Slotman BJ, Senan S. Time for reappraisal of extracranial treatment options? Synchronous brain metastases from nonsmall cell lung cancer. Cancer (2011) 117(3):597-605. doi:10.1002/ cncr. 25416

6. Jamal-Hanjani M, Spicer J. Epidermal growth factor receptor tyrosine kinase inhibitors in the treatment of epidermal growth factor receptor-mutant nonsmall cell lung cancer metastatic to the brain. Clin Cancer Res (2012) 18(4):938-44. doi:10.1158/1078-0432.ccr-11-2529

7. Gaspar L, Scott C, Rotman M, Asbell S, Phillips T, Wasserman T, et al. Recursive partitioning analysis (RPA) of prognostic factors in three Radiation Therapy Oncology Group (RTOG) brain metastases trials. Int J Radiat Oncol Biol Phys (1997) 37(4):745-51. doi:10.1016/S0360-3016(96)00619-0

8. Weltman E, Salvajoli JV, Brandt RA, de Morais Hanriot R, Prisco FE, Cruz JC, et al. Radiosurgery for brain metastases: a score index for predicting prognosis. Int J Radiat Oncol Biol Phys (2000) 46(5):1155-61. doi:10.1016/S0360-3016(99) 00549-0

9. Lorenzoni J, Devriendt D, Massager N, David P, Ruiz S, Vanderlinden B, et al. Radiosurgery for treatment of brain metastases: estimation of patient eligibility using three stratification systems. Int J Radiat Oncol Biol Phys (2004) 60(1):218-24. doi:10.1016/j.ijrobp.2004.02.017

10. Sperduto PW, Berkey B, Gaspar LE, Mehta M, Curran W. A new prognostic index and comparison to three other indices for patients with brain metastases: an analysis of 1,960 patients in the RTOG database. Int J Radiat Oncol Biol Phys (2008) 70(2):510-4. doi:10.1016/j.ijrobp.2007.06.074

11. Rades D, Dunst J, Schild SE. A new scoring system to predicting the survival of patients treated with whole-brain radiotherapy for brain metastases. Strahlenther Onkol (2008) 184(5):251-5. doi:10.1007/s00066-008-1831-5

12. Viani GA, da Silva LG, Stefano EJ. Prognostic indexes for brain metastases: which is the most powerful? Int J Radiat Oncol Biol Phys (2012) 83(3):e325-30. doi:10.1016/j.ijrobp.2011.12.082

13. Coate LE, John T, Tsao M-S, Shepherd FA. Molecular predictive and prognostic markers in non-small-cell lung cancer. Lancet Oncol (2009) 10(10):1001-10. doi:10.1016/S1470-2045(09)70155-X
14. Zhu CQ, Ding K, Strumpf D, Weir BA, Meyerson M, Pennell N, et al. Prognostic and predictive gene signature for adjuvant chemotherapy in resected non-smallcell lung cancer. J Clin Oncol (2010) 28(29):4417-24. doi:10.1200/jco.2009.26. 4325

15. Temel JS, Greer JA, Muzikansky A, Gallagher ER, Admane S, Jackson VA, et al. Early palliative care for patients with metastatic non-small-cell lung cancer. $N$ Engl J Med (2010) 363(8):733-42. doi:10.1056/NEJMoa1000678

16. Ryken TC, McDermott M, Robinson PD, Ammirati M, Andrews DW, Asher AL, et al. The role of steroids in the management of brain metastases: a systematic review and evidence-based clinical practice guideline. J Neurooncol (2010) 96(1):103-14. doi:10.1007/s11060-009-0057-4

17. Patchell RA, Tibbs PA, Walsh JW, Dempsey RJ, Maruyama Y, Kryscio RJ, et al. A randomized trial of surgery in the treatment of single metastases to the brain. N Engl J Med (1990) 322(8):494-500. doi:10.1056/nejm199002223220802

18. Vecht CJ, Haaxma-Reiche H, Noordijk EM, Padberg GW, Voormolen JH, Hoekstra FH, et al. Treatment of single brain metastasis: radiotherapy alone or combined with neurosurgery? Ann Neurol (1993) 33(6):583-90. doi:10.1002/ana. 410330605

19. Mintz AH, Kestle J, Rathbone MP, Gaspar L, Hugenholtz H, Fisher B, et al. A randomized trial to assess the efficacy of surgery in addition to radiotherapy in patients with a single cerebral metastasis. Cancer (1996) 78(7):1470-6. doi:10. 1002/(SICI)1097-0142(19961001)78:7<1470::AID-CNCR14>3.0.CO;2-X

20. Brown PD, Pugh S, Laack NN, Wefel JS, Khuntia D, Meyers C, et al. Memantine for the prevention of cognitive dysfunction in patients receiving wholebrain radiotherapy: a randomized, double-blind, placebo-controlled trial. Neuro Oncol (2013) 15(10):1429-37. doi:10.1093/neuonc/not114

21. Gondi V, Tome WA, Marsh J, Struck A, Ghia A, Turian JV, et al. Estimated risk of perihippocampal disease progression after hippocampal avoidance during whole-brain radiotherapy: safety profile for RTOG 0933. Radiother Oncol (2010) 95(3):327-31. doi:10.1016/j.radonc.2010.02.030

22. Andrews DW, Scott CB, Sperduto PW, Flanders AE, Gaspar LE, Schell MC, et al. Whole brain radiation therapy with or without stereotactic radiosurgery boost for patients with one to three brain metastases: phase III results of the RTOG 9508 randomised trial. Lancet (2004) 363(9422):1665-72. doi:10.1016/s01406736(04)16250-8

23. Chougule P, Burton-Williams M, Saris M. Randomized treatment of brain metastases with gamma knife radiosurgery, whole brain radiotherapy or both. Int J Radiat Oncol Biol Phys (2000) 48:114. doi:10.1016/S0360-3016(00)80024-3

24. Patchell RA, Tibbs PA, Regine WF, Dempsey RJ, Mohiuddin M, Kryscio RJ, et al. Postoperative radiotherapy in the treatment of single metastases to the brain: a randomized trial. JAMA (1998) 280(17):1485-9.

25. Khuntia D, Brown P, Li J, Mehta MP. Whole-brain radiotherapy in the management of brain metastasis. J Clin Oncol (2006) 24(8):1295-304. doi:10.1200/jco. 2005.04.6185

26. Borgelt B, Gelber R, Kramer S, Brady LW, Chang CH, Davis LW, et al. The palliation of brain metastases: final results of the first two studies by the Radiation Therapy Oncology Group. Int J Radiat Oncol Biol Phys (1980) 6(1):1-9. doi:10.1016/0360-3016(80)90195-9

27. Borgelt B, Gelber R, Larson M, Hendrickson F, Griffin T, Roth R. Ultra-rapid high dose irradiation schedules for the palliation of brain metastases: final results of the first two studies by the Radiation Therapy Oncology Group. Int J Radiat Oncol Biol Phys (1981) 7(12):1633-8. doi:10.1016/0360-3016(81)90184-X

28. Kurtz JM, Gelber R, Brady LW, Carella RJ, Cooper JS. The palliation of brain metastases in a favorable patient population: a randomized clinical trial by the Radiation Therapy Oncology Group. Int J Radiat Oncol Biol Phys (1981) 7(7):891-5. doi:10.1016/0360-3016(81)90005-5

29. Harwood AR, Simson WJ. Radiation therapy of cerebral metastases: a randomized prospective clinical trial. Int J Radiat Oncol Biol Phys (1977) 2(1112):1091-4. doi:10.1016/0360-3016(77)90114-6

30. Chatani M, Matayoshi Y, Masaki N, Inoue T. Radiation therapy for brain metastases from lung carcinoma. Prospective randomized trial according to the level of lactate dehydrogenase. Strahlentherap Onkol (1994) 170(3):155-61.

31. Haie-Meder C, Pellae-Cosset B, Laplanche A, Lagrange JL, Tuchais C, Nogues $\mathrm{C}$, et al. Results of a randomized clinical trial comparing two radiation schedules in the palliative treatment of brain metastases. Radiother Oncol (1993) 26(2):111-6. doi:10.1016/0167-8140(93)90091-L

32. Meyers CA, Smith JA, Bezjak A, Mehta MP, Liebmann J, Illidge T, et al. Neurocognitive function and progression in patients with brain metastases treated 
with whole-brain radiation and motexafin gadolinium: results of a randomized phase III trial. J Clin Oncol (2004) 22(1):157-65. doi:10.1200/jco.2004.05.128

33. McDuff SG, Taich ZJ, Lawson JD, Sanghvi P, Wong ET, Barker FG II, et al. Neurocognitive assessment following whole brain radiation therapy and radiosurgery for patients with cerebral metastases. J Neurol Neurosurg Psychiatry (2013) 84(12):1384-91. doi:10.1136/jnnp-2013-305166

34. Aoyama H, Shirato H, Tago M, Nakagawa K, Toyoda T, Hatano K, et al. Stereotactic radiosurgery plus whole-brain radiation therapy vs stereotactic radiosurgery alone for treatment of brain metastases: a randomized controlled trial. JAMA (2006) 295(21):2483-91. doi:10.1001/jama.295.21.2483

35. Chang EL, Wefel JS, Hess KR, Allen PK, Lang FF, Kornguth DG, et al. Neurocognition in patients with brain metastases treated with radiosurgery or radiosurgery plus whole-brain irradiation: a randomised controlled trial. Lancet Oncol (2009) 10(11):1037-44. doi:10.1016/s1470-2045(09)70263-3

36. Kocher M, Soffietti R, Abacioglu U, Villa S, Fauchon F, Baumert BG, et al. Adjuvant whole-brain radiotherapy versus observation after radiosurgery or surgical resection of one to three cerebral metastases: results of the EORTC 22952-26001 study. J Clin Oncol (2011) 29(2):134-41. doi:10.1200/jco.2010.30.1655

37. Walbert T, Gilbert MR. The role of chemotherapy in the treatment of patients with brain metastases from solid tumors. Int J Clin Oncol (2009) 14(4):299-306. doi:10.1007/s10147-009-0916-1

38. van den Bent MJ. The role of chemotherapy in brain metastases. Eur J Cancer (2003) 39(15):2114-20. doi:10.1016/S0959-8049(03)00577-X

39. Gerstner ER, Fine RL. Increased permeability of the blood-brain barrier to chemotherapy in metastatic brain tumors: establishing a treatment paradigm. J Clin Oncol (2007) 25(16):2306-12. doi:10.1200/jco.2006.10.0677

40. Barlesi F, Gervais R, Lena H, Hureaux J, Berard H, Paillotin D, et al. Pemetrexed and cisplatin as first-line chemotherapy for advanced non-small-cell lung cancer (NSCLC) with asymptomatic inoperable brain metastases: a multicenter phase II trial (GFPC 07-01). Ann Oncol (2011) 22(11):2466-70. doi:10.1093/annonc/mdr003

41. Dinglin XX, Huang Y, Liu H, Zeng YD, Hou X, Chen LK. Pemetrexed and cisplatin combination with concurrent whole brain radiotherapy in patients with brain metastases of lung adenocarcinoma: a single-arm phase II clinical trial. J Neurooncol (2013) 112(3):461-6. doi:10.1007/s11060-013-1079-5

42. Ettinger DS, Akerley W, Borghaei H, Chang AC, Cheney RT, Chirieac LR, et al. Non-small cell lung cancer, version 2.2013. J Natl Compr Canc Netw (2013) 11(6):645-53.

43. Kohler J, Schuler M. Afatinib, erlotinib and gefitinib in the first-line therapy of EGFR mutation-positive lung adenocarcinoma: a review. Onkologie (2013) 36(9):510-8. doi:10.1159/000354627

44. Mok TS, Wu YL, Thongprasert S, Yang CH, Chu DT, Saijo N, et al. Gefitinib or carboplatin-paclitaxel in pulmonary adenocarcinoma. N Engl J Med (2009) 361(10):947-57. doi:10.1056/NEJMoa0810699

45. Rosell R, Carcereny E, Gervais R, Vergnenegre A, Massuti B, Felip E, et al. Erlotinib versus standard chemotherapy as first-line treatment for European patients with advanced EGFR mutation-positive non-small-cell lung cancer (EURTAC): a multicentre, open-label, randomised phase 3 trial. Lancet Oncol (2012) 13(3):239-46. doi:10.1016/s1470-2045(11)70393-x

46. Sequist LV, Yang JC, Yamamoto N, O’Byrne K, Hirsh V, Mok T, et al. Phase III study of afatinib or cisplatin plus pemetrexed in patients with metastatic lung adenocarcinoma with EGFR mutations. J Clin Oncol (2013) 31(27):3327-34. doi:10.1200/jco.2012.44.2806

47. Yang JC, Hirsh V, Schuler M, Yamamoto N, O’Byrne KJ, Mok TS, et al. Symptom control and quality of life in LUX-lung 3: a phase III study of afatinib or cisplatin/pemetrexed in patients with advanced lung adenocarcinoma with EGFR mutations. J Clin Oncol (2013) 31(27):3342-50. doi:10.1200/jco.2012.46.1764
48. Shaw AT, Kim DW, Nakagawa K, Seto T, Crino L, Ahn MJ, et al. Crizotinib versus chemotherapy in advanced ALK-positive lung cancer. N Engl J Med (2013) 368(25):2385-94. doi:10.1056/NEJMoal214886

49. Shaw AT, Kim DW, Mehra R, Tan DS, Felip E, Chow LQ, et al. Ceritinib in ALKrearranged non-small-cell lung cancer. N Engl J Med (2014) 370(13):1189-97. doi:10.1056/NEJMoal311107

50. Luo D, Ye X, Hu Z, Peng K, Song Y, Yin X, et al. EGFR mutation status and its impact on survival of Chinese non-small cell lung cancer patients with brain metastases. Tumour Biol (2014) 35(3):2437-44. doi:10.1007/s13277-013$1323-9$

51. Eichler AF, Kahle KT, Wang DL, Joshi VA, Willers H, Engelman JA, et al. EGFR mutation status and survival after diagnosis of brain metastasis in nonsmall cell lung cancer. Neuro Oncol (2010) 12(11):1193-9. doi:10.1093/neuonc/noq076

52. Oskan F, Ganswindt U, Schwarz SB, Manapov F, Belka C, Niyazi M. Hippocampus sparing in whole-brain radiotherapy. Strahlenther Onkol (2014) 190(4):337-41. doi:10.1007/s00066-013-0518-8

53. O'Flaherty JD, Gray S, Richard D, Fennell D, O'Leary JJ, Blackhall FH, et al. Circulating tumour cells, their role in metastasis and their clinical utility in lung cancer. Lung Cancer (2012) 76(1):19-25. doi:10.1016/j.lungcan.2011.10.018

54. Sundar R, Soong R, Cho B-C, Brahmer JR, Soo RA. Immunotherapy in the treatment of non-small cell lung cancer. Lung Cancer (2014) 85(2):101-9. doi:10.1016/j.lungcan.2014.05.005

55. Shepherd FA, Douillard JY, Blumenschein GR Jr. Immunotherapy for non-small cell lung cancer: novel approaches to improve patient outcome. J Thorac Oncol (2011) 6(10):1763-73. doi:10.1097/JTO.0b013e31822e28fc

56. Eldredge HB, Denittis A, Duhadaway JB, Chernick M, Metz R, Prendergast GC. Concurrent whole brain radiotherapy and short-course chloroquine in patients with brain metastases: a pilot trial. J Radiat Oncol (2013) 2:315-21. doi:10.1007/s13566-013-0111-x

57. Garon EB, Christofk HR, Hosmer W, Britten CD, Bahng A, Crabtree MJ, et al. Dichloroacetate should be considered with platinum-based chemotherapy in hypoxic tumors rather than as a single agent in advanced non-small cell lung cancer. J Cancer Res Clin Oncol (2014) 140(3):443-52. doi:10.1007/s00432-014$1583-9$

58. Blumenschein GR Jr. Developmental antiangiogenic agents for the treatment of non-small cell lung cancer (NSCLC). Invest New Drugs (2012) 30(4):1802-11. doi:10.1007/s10637-011-9750-1

59. Berge EM, Doebele RC. Targeted therapies in non-small cell lung cancer: emerging oncogene targets following the success of epidermal growth factor receptor. Semin Oncol (2014) 41(1):110-25. doi:10.1053/j.seminoncol.2013.12.006

Conflict of Interest Statement: The authors declare that the research was conducted in the absence of any commercial or financial relationships that could be construed as a potential conflict of interest.

Received: 28 April 2014; accepted: 01 September 2014; published online: 15 September 2014.

Citation: Owen S and Souhami L (2014) The management of brain metastases in non-small cell lung cancer. Front. Oncol. 4:248. doi: 10.3389/fonc.2014.00248

This article was submitted to Thoracic Oncology, a section of the journal Frontiers in Oncology.

Copyright $\odot 2014$ Owen and Souhami. This is an open-access article distributed under the terms of the Creative Commons Attribution License (CC BY). The use, distribution or reproduction in other forums is permitted, provided the original author(s) or licensor are credited and that the original publication in this journal is cited, in accordance with accepted academic practice. No use, distribution or reproduction is permitted which does not comply with these terms. 